\title{
Postgraduate students attitude about dating and wedding ceremonies
}

\author{
SUMANGALA BADAMI AND VISHALA PATNAM
}

Received: 07.07.2014; Revised: 10.10.2014; Accepted: 23.10 .2014

See end of the paper for authors' affiliations

SUMANGALA BADAMI

Department of Human

Development and Family Studies,

College of Rural Home Science,

University of Agricultural

Sciences, DHARWAD

(KARNATAKA) INDIA

Email:badami.sumangala8@gmail

com
ABSTRACT : Three hundred Maharashtrian postgraduate students (21-26 yrs) were chosen at random from purposely selected seven colleges of Parbhani town, Maharashtra state. The data were collected personally interviewing the P.G. students based on the interview schedule cum checklist. Irrespective of SES, 45 per cent P.G. boys and 32 per cent P.G. girls opined to have traditional-cum-registered method of wedding ceremony for the reason that, it is a safe method and also helps in maintenance of Indian culture. Significantly a higher percentages of P.G. boys desired to have traditional-cum-registered wedding ceremony as compared to their counterpart P.G. girls. Irrespective of SES, 73-77 per cent P.G. boys and girls wanted to date with fiancée / fiancé for different reasons. No significant differences were found in the views of P.G. boys and girls about dating with fiancée and fiancé and in the reasons for it, respectively, based on their socio-economic status. Irrespective of SES, 83-89 per cent P.G. boys and girls opined that there should be time gap of 1-2 yrs between engagement and marriage ceremonies for different reasons. No significant differences were noticed in the opinions of P.G. boys and girls about time gap required between engagement and marriage ceremonies.

KEY WORDS: Dating, Marriage trends, Mate selection, Marital relationships

口 HOW TO CITE THIS PAPER : Badami, Sumangala and Patnam, Vishala (2014). Postgraduate students attitude about dating and wedding ceremonies. Asian J. Home Sci., 9 (2) : 477-480. 